\title{
Validation of the Japanese version of the barriers questionnaire II in cancer pain management: a cross-sectional study
}

\author{
Naoki Sakakibara ${ }^{1,2^{*}}$ D, Hiroko Komatsu ${ }^{3}$, Mikako Takahashi ${ }^{4}$, Hideko Yamauchi ${ }^{5}$, Teruo Yamauchi ${ }^{6}$ and \\ Ardith Z. Doorenbos ${ }^{7,8}$
}

\begin{abstract}
Background: The Barriers Questionnaire II (BQ-II) was developed to assess barriers to effective pain management. In this study, we aimed to assess the reliability and validity of the newly developed Japanese version of the BQ-II (JBQ-II).

Methods: This study used a cross-sectional design. The study was conducted an ambulatory infusion center for cancer in a general hospital in Tokyo, Japan. Participants were 120 Japanese patients with cancer and 21 Japanese health professionals with experience in pain management. Cronbach's alpha coefficient was used to calculate reliability. Testretest reliability was assessed with Spearman's intra-class correlation coefficient (ICC). Construct, criterion-related, and discriminant validity were assessed using information about pain management, daily life, mental health, and subjective health.

Results: The Cronbach's alpha was 0.90 for the JBQ-II, and all ICCs exceeded $0.70(P<0.01)$. Factor analysis showed the JBQ-II had a virtually identical structure to the BQ-II, and path analysis supported the JBQ-II constructs. The JBQ-II was weakly correlated with poor mental state $(r=0.36, P<0.01)$. Patients' JBQ-II scores were significantly higher than health professionals' scores.

Conclusion: The JBQ-II is a valid and reliable measure of patient-related barriers to pain management among Japanese adult patients with cancer.
\end{abstract}

Keywords: Cancer, Pain management, Barriers, Palliative care, Analgesics, Japan

\section{Background}

Pain is a symptom commonly experienced by patients with cancer [1]. However, in Japan, patients' pain is poorly controlled [2]. Patient-related barriers toward pain management contribute to suboptimal pain relief. These barriers include psychological constructs (e.g., beliefs and values) that affect patients' pain reporting,

\footnotetext{
*Correspondence: nsakakib@ncc.go.jp

1 Analysis Section, Center for Cancer Registries, Center for Cancer Control and Information Services, National Cancer Center Japan, 5-1-1 Tsukiji, Chuo-ku, Tokyo 104-0045, Japan

${ }^{2}$ St. Luke's International Hospital, 9-1 Akashi-cho, Chuo-ku, Tokyo 104-8560, Japan

Full list of author information is available at the end of the article
}

requests for pain management, and use of analgesics, thereby leading to inadequate pain control [3-5]. A previous study reported that Japanese patients with cancer are reluctant to report pain and seek analgesic use [2].

The Barriers Questionnaire (BQ) and the Barriers Questionnaire II (BQ-II) were developed to determine patient-related barriers to cancer pain management. These instruments have been translated and used in many countries [6-13]. However, no such tools to assess patient-related barriers to cancer pain management were available in Japan. We developed a Japanese version of the BQ-II (JBQ-II) to identify patient-related barriers to pain management among Japanese patients with cancer.

(c) The Author(s). 2020 Open Access This article is licensed under a Creative Commons Attribution 4.0 International License, which permits use, sharing, adaptation, distribution and reproduction in any medium or format, as long as you give appropriate credit to the original author(s) and the source, provide a link to the Creative Commons licence, and indicate if changes were made. The images or other third party material in this article are included in the article's Creative Commons licence, unless indicated otherwise in a credit line to the material. If material is not included in the article's Creative Commons licence and your intended use is not permitted by statutory regulation or exceeds the permitted use, you will need to obtain permission directly from the copyright holder. To view a copy of this licence, visit http://creativecommons.org/licenses/by/4.0/. The Creative Commons Public Domain Dedication waiver (http://creativecommons.org/publicdomain/zero/1.0/) applies to the data made available in this article, unless otherwise stated in a credit line to the data. 
This study aimed to evaluate the reliability and validity of the JBQ-II.

\section{Methods}

\section{Participants, setting, and recruitment}

This study used a cross-sectional design. Approval was obtained from the institutional review boards of Keio University (No. 2012-10) and St. Luke's International Hospital (No. 12-R066). Participation in this study was voluntary. All participants provided informed consent before participating.

Patients with cancer were recruited from an ambulatory infusion center for cancer in a general hospital in Tokyo, Japan. Eligibility criteria were patients: a) aged 20 years or older; b) able to speak and read Japanese; c) with a diagnosis of metastatic or advanced cancer; (d) with an Eastern Cooperative Oncology Group performance status of 2 or less; and (e) with a pain rating of 1 or higher (on a $0-10$ scale) in the previous week. Clinical staff identified eligible patients. An impartial researcher described the study to potential participants and obtained consent.

Health professional participants were recruited from the same hospital. The hospital manager was responsible for recruiting these participants. Inclusion criteria were professionals with a valid license as a physician, nurse, or pharmacist, and at least 3 years of experience in providing pain management. A participation request form and an anonymous questionnaire were sent to identified health professionals who met the inclusion criteria. Health professionals who submitted completed questionnaires were considered to have consented to participate in the study.

\section{Data collection}

Patient participants received a packet of questionnaires that included the JBQ-II, the Japanese version of the Brief Pain Inventory (BPI-J), the six-item Kessler Psychological Distress Scale (K6), and the Subjective Health Scale. Patients completed the questionnaires during a hospital visit and returned them to the researchers. To confirm the test-retest reliability of the JBQ-II, the first 20 patient participants were asked to complete the JBQII a second time after a 2-week interval.

An anonymous, self-administered questionnaire was distributed to potential health professional participants. This group was asked to complete the JBQ-II as if they were patients with cancer experiencing pain. The health professionals' questionnaire also covered age, sex, education, length of occupational experience, and length of palliative care experience. Health professional participants completed the questionnaires in their own time and returned them to the researchers by hospital post.

\section{Measures}

The questionnaire used in this survey was created by combining the following tools.

\section{Patients}

JBQ-II The BQ-II is a 27-item instrument that measures patients' beliefs about cancer pain and use of analgesics [4]. The BQ-II was developed as an updated version of the $B Q$ [3], based on changes in pain management practices, developments in the literature, and feedback from patients across multiple studies. Participants are asked to rate the extent to which they agree with each statement on a Likert scale from 0 (disagree) to 5 (strongly agree). Total and subscale scores are calculated, with higher scores indicating stronger barriers. The BQ-II comprises four subscales covering physiological effects, communication, harmful effects, and fatalism.

Consent to translate the BQ-II into Japanese was obtained from the original author of the BQ-II. The JBQ-II passed through a process of double back translations, was Japanized, and the content verified by the original author. Finally, clinical and research experts examined the content and validity of the JBQ-II. When the BQ-II was developed, the three-item "disease progression" BQ subscale was removed. However, this subscale was returned when the BQ-II was translated into Japanese, making the JBQ-II a 30 -item instrument. Disease progression was considered an item culturally relevant in Japan because of Japanese patients' attitudes toward cancer pain.

BPI-J The BPI is a reliable and valid scale used to assess pain intensity and its effect on daily living; higher scores indicate interference in daily life. This scale is used worldwide [14-18], including in Japan [19].

Pain Management Index (PMI) The PMI is a scale used worldwide to evaluate pain management [20, 21]. It is based on the World Health Organization pain ladder and BPI pain scores [22]. The scale ranges from -3 (e.g., a patient in severe pain who has not received an analgesic) to +3 (e.g., a patient who has taken a strong opioid and is not reporting any pain).

K6 The K6 has six questions covering a person's emotional state, and has been validated in Japan [23, 24]. Each question is scored from 0 (none of the time) to 4 (all of the time). A total score is calculated, with higher scores indicating poor mental health.

Subjective health scale The Subjective Health Scale is a self-assessment of health with four options: "In very good health," "In fairly good health," "Not in very good 
health," and "Not in good health at all." The categorization method for this self-assessment of health is frequently used in Japan [25].

\section{Health professionals}

Health professionals were asked to answer the JBQ-II subjectively, as if they were a patient with cancer experiencing pain. Information was collected on the appropriateness of the JBQ-II as well as on participant characteristics, length of occupational experience, and length of palliative care experience.

\section{Data analysis}

Descriptive statistics for each JBQ-II item were calculated to examine ceiling or floor effects and verify that each item reflected the trend of respondents. Reliability was determined by internal consistency using Cronbach's alpha coefficient, with test-retest reliability assessed using Spearman's intra-class correlation coefficient (ICC). Construct, discriminant, and criterion-related validity were also assessed.

Construct validity was evaluated in two different ways to verify whether it was possible to make theoretical predictions about the concept of a barrier. First, we performed exploratory factor analysis using the principal method and promax rotation, which was the method used for the original scale. The fit of the factor model was evaluated based on the results of the screen test, interpretability, and examination of residuals. Although the $\mathrm{BQ}-\mathrm{II}$ is a 27 -item scale, 30 items (including the three disease progression items) were used for the JBQII factor analysis.
Next, we used path analysis by structural equation modeling to examine a structural model for pain, barriers, and quality of life (QoL), which was developed based on previous studies (Fig. 1) [4, 5, 11]. Barriers to pain management were positioned as psychological constructs (e.g., beliefs and values) toward a threat. This model postulated that strong barriers hinder the use of analgesics as a means of dealing with pain, leading to insufficient pain management. This affects emotional state, daily activities, and subjective health, and QoL declines $[4,5,11]$. We considered subjective health, emotional state (K6), and daily life (BPI) as potential QoL variables, because these factors influence QoL $[5,11]$. The path analysis was conducted for 108 patient participants, after excluding 12 who used strong opioids and experienced medium or more severe pain.

The known group method was conducted to explore discriminant validity [4]. Two groups were established: patients were classified as Group A, and a known group of health professionals with special knowledge and training who were serving as patient educators were classified as Group B. The Mann-Whitney U test was used to investigate differences between the two groups' total scores and the scores for each JBQ-II factor. In theory, Group A scores were expected to be higher than Group B scores.

Regarding criterion-related validity, there were no studies available in Japan to assess associations between the barriers score and outcome measures. Therefore, Pearson's correlation coefficients for the JBQ-II and K6 domains were calculated. The $\mathrm{K} 6$ was chosen as an external index because a barrier is a psychological concept. It was proposed that conceptually-related domains would be weakly

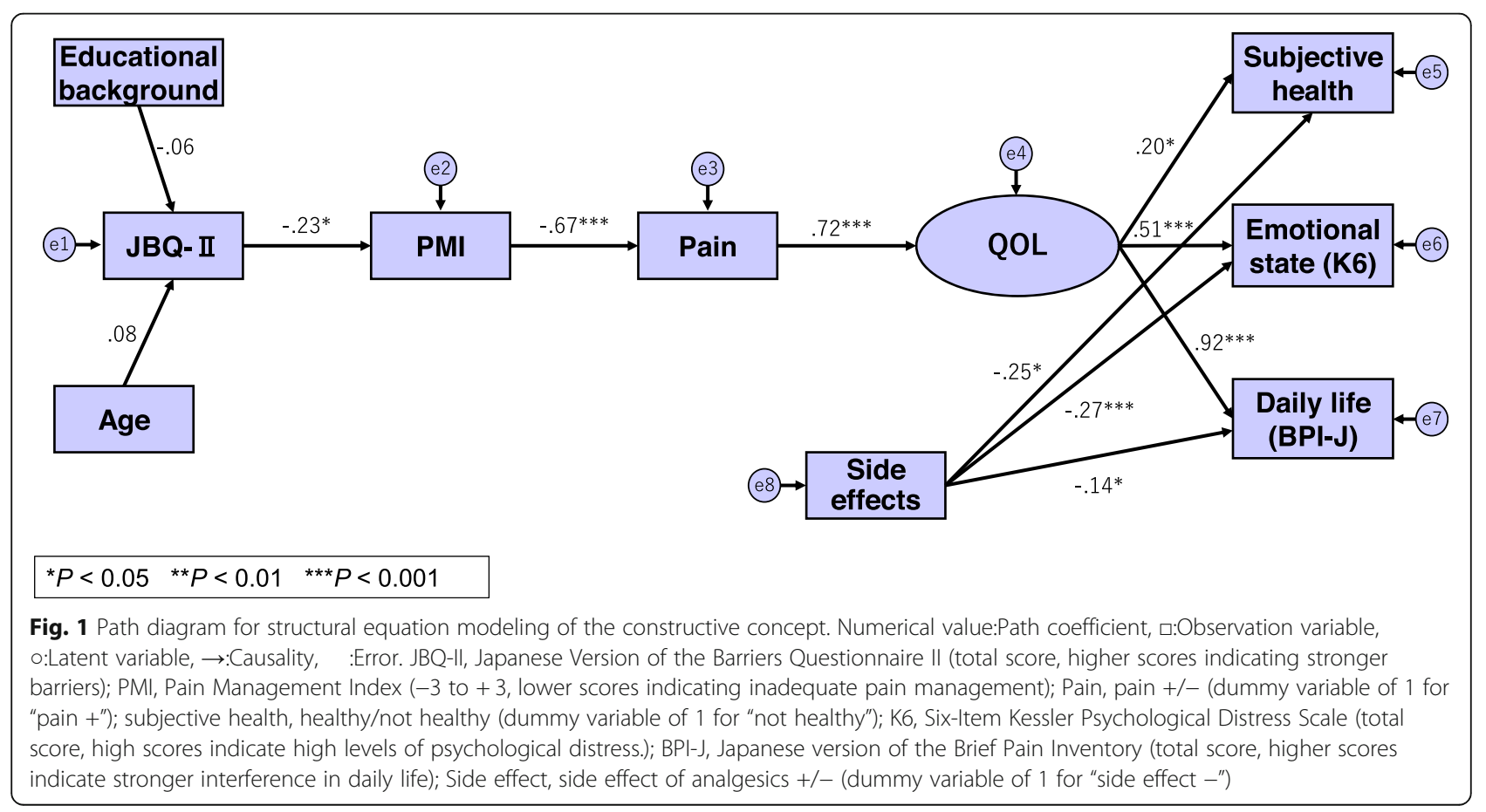


correlated with each other. In addition, we asked participants to comment on the feasibility and appropriateness of expression of the JBQ-II. Participants were asked whether the JBQ-II content was clear and easy to understand, whether they found it easy to answer the questionnaire, and how long it took to complete the JBQ-II.

\section{Results}

Questionnaires were distributed to 134 patients, and 123 $(91.8 \%)$ responded. Valid responses were received from 120 of these respondents (97.5\%), after excluding those with missing values or extreme bias. Questionnaires were distributed to 26 health professionals, and 21 (80.8\%) responded. Table 1 shows that the patients' mean age was 56.6

Table 1 Characteristics of patient participants $(N=120)$

\begin{tabular}{|c|c|c|c|}
\hline & & & $\boldsymbol{N}=120$ \\
\hline Demographics & & $n$ & $(\%)$ \\
\hline Age & $30-39$ & 7 & $(5.8)$ \\
\hline \multirow[t]{4}{*}{$(56.6 \pm S D$ 11.57) } & $40-49$ & 28 & $(23.4)$ \\
\hline & $50-59$ & 33 & $(27.5)$ \\
\hline & $60-69$ & 30 & $(25.0)$ \\
\hline & $70-89$ & 22 & $(18.3)$ \\
\hline \multirow[t]{2}{*}{ Sex } & Male & 25 & $(20.8)$ \\
\hline & Female & 95 & $(79.2)$ \\
\hline \multirow[t]{3}{*}{ Highest education level } & Middle/High school & 32 & $(26.7)$ \\
\hline & Vocational school/jr. college & 43 & $(35.8)$ \\
\hline & University/graduate school & 45 & $(37.5)$ \\
\hline Disease & & $n$ & $(\%)$ \\
\hline \multirow[t]{4}{*}{ Diagnosis } & Breast & 85 & $(70.8)$ \\
\hline & Digestive system & 22 & $(18.3)$ \\
\hline & Urological & 11 & $(9.2)$ \\
\hline & Other & 2 & $(1.7)$ \\
\hline \multirow[t]{3}{*}{ Stage } & Stage IV & 111 & $(92.5)$ \\
\hline & Stage IIIC & 6 & $(5.0)$ \\
\hline & Stage IIIb & 3 & $(2.5)$ \\
\hline \multirow[t]{3}{*}{ Metastasis } & Yes & 110 & $(91.7)$ \\
\hline & (Bone metastasis) & 67 & $(57.5)$ \\
\hline & No & 10 & $(8.3)$ \\
\hline \multirow[t]{3}{*}{$\mathrm{PS}^{\mathrm{a}}$} & 0 & 73 & $(60.8)$ \\
\hline & 1 & 40 & $(33.3)$ \\
\hline & 2 & 7 & $(5.8)$ \\
\hline \multirow[t]{4}{*}{ Drugs used } & No analgesics used ${ }^{b}$ & 46 & $(38.3)$ \\
\hline & Non-opioids & 57 & $(46.6)$ \\
\hline & Weak opioids & 7 & $(5.8)$ \\
\hline & Strong opioids & 26 & $(21.7)$ \\
\hline
\end{tabular}

\footnotetext{
${ }^{a}$ Eastern Cooperative Oncology Group performance status

b This category includes "Analgesics prescribed but patient has elected not to use," "Experiencing pain but no analgesics prescribed," and "Had no pain on the day of the survey"
}

(standard deviation [SD] 11.65) years, and 79.7\% were female. The majority of patient participants $(73.3 \%)$ were well educated. The most frequently identified diagnoses were breast cancer $(70.8 \%)$, digestive system cancer $(18.3 \%)$, and urological cancer (9.2\%). Most patients (91.7\%) had metastatic disease, and more than half had bone metastases.

Health professional participants had a mean age of 33.67 (SD 9.12) years, mean health care experience of 10.81 (SD 9.02) years, and mean palliative care experience of 5.10 (SD 3.18) years. Most of these participants (90.5\%) were female.

\section{JBQ-II score \\ Patients}

The internal consistency for the JBQ-II in the patient sample was 0.90 . Total JBQ-II scores ranged from 10 to 98 (possible range 0-150), with a mean of 59.18 (SD 21.22). Analyses were performed to determine whether patients' JBQ-II scores were related to demographic variables, including age, gender, education, marital status, type of cancer diagnosis, and other significant health problems. The only demographic variable that was correlated with total JBQ-II score was a history of previous immunotherapy $(\rho=-0.19, P<0.05)$, which tended to be associated with higher total JBQ-II scores. The JBQ-II total score for patients with previous immunotherapy $(n=21)$ was 64.7 (SD 19.64), whereas that for patients without previous immunotherapy $(n=99)$ was 54.10 (SD 19.95), showing a significant difference between the two groups $(P=0.04)$.

The mean and SD of the individual items of the JBQII, floor and ceiling scores, measures of skewness and kurtosis, and I-T correlation data for each item for the total sample are presented in Table 2. The measures of skewness and kurtosis indicated that most items did not show marked deviation from a normal distribution.

\section{Health professionals}

The internal consistency for the JBQ-II total score for the health professional sample was 0.90 . The mean total JBQ-II score in these participants was 22.1 (SD 14.79), with total scores ranging from 0 to 51 . There were no associations between health professionals' demographic variables (age, gender, education, years in health care, and years in palliative care) and total JBQ-II scores.

\section{Reliability verification Internal consistency}

Cronbach's alpha coefficients were 0.90 for the total scale, 0.89 for physiological effects (Factor I), 0.78 for communication (Factor II), 0.86 for harmful effects (Factor III), 0.92 for disease progression (Factor IV), and 0.73 for fatalism (Factor V) (Table 3). 
Table 2 Means, standard deviations, floor and ceiling percentages, skewness, kurtosis, and I-T correlation of the Japanese version of the Barriers Questionnaire-II (total sample)

\begin{tabular}{|c|c|c|c|c|c|c|c|c|}
\hline \multirow{2}{*}{$\begin{array}{l}\text { No } \\
1\end{array}$} & \multirow{2}{*}{$\begin{array}{l}\text { Items } \\
\text { Fatalism } 1\end{array}$} & \multicolumn{2}{|c|}{ Mean(SD) } & \multirow{2}{*}{$\begin{array}{l}\text { Floor (\%) } \\
38.33\end{array}$} & \multirow{2}{*}{$\begin{array}{l}\text { Celling (\%) } \\
1.67\end{array}$} & \multirow{2}{*}{$\begin{array}{l}\text { Skewness } \\
0.74\end{array}$} & \multirow{2}{*}{$\begin{array}{l}\text { Kurtosis } \\
0.22\end{array}$} & \multirow{2}{*}{$\begin{array}{l}1-T^{a} \\
\text { correlation } \\
0.27^{* *}\end{array}$} \\
\hline & & 0.97 & $(0.94)$ & & & & & \\
\hline 2 & Harmful Effects: Addiction 1 & 2.81 & $(1.42)$ & 7.50 & 10.00 & -0.43 & -0.66 & $0.48^{* *}$ \\
\hline 3 & Physiological Effects: SE1 (Drowsiness) & 2.78 & (1.36) & 8.33 & 7.50 & -0.49 & -0.45 & $0.32^{* *}$ \\
\hline 4 & Harmful Effects: Immune system 1 & 2.23 & $(1.51)$ & 21.67 & 4.17 & -0.20 & -1.11 & $0.69^{* *}$ \\
\hline 5 & Physiological Effects: SE2 (Confusion) & 2.23 & (1.46) & 19.17 & 4.17 & -0.17 & -0.97 & $0.71^{* *}$ \\
\hline 6 & Physiological Effects: Tolerance 1 & 3.21 & $(1.31)$ & 4.17 & 12.50 & -0.81 & 0.02 & $0.61^{* *}$ \\
\hline 7 & Physiological Effects: Monitor 1 & 2.64 & (1.52) & 11.67 & 11.67 & -0.23 & -0.90 & $0.61^{* *}$ \\
\hline 8 & Fatalism 2 & 1.33 & $(1.28)$ & 28.33 & 5.00 & 1.23 & 1.47 & 0.11 \\
\hline 9 & Harmful Effects: Addiction 2 & 2.55 & (1.46) & 14.17 & 6.67 & -0.36 & -0.76 & $0.57^{* *}$ \\
\hline 10 & Physiological Effects: SE3 (Nausea) & 1.98 & $(1.32)$ & 15.83 & 3.33 & 0.16 & -0.67 & $0.44^{* *}$ \\
\hline 11 & Communication: Be good 1 & 1.32 & $(1.61)$ & 50.00 & 6.67 & 0.92 & -0.38 & $0.41^{* *}$ \\
\hline 12 & Communiation: Distract MD 1 & 0.74 & $(1.18)$ & 62.50 & 1.67 & 1.65 & 2.11 & $0.48^{* *}$ \\
\hline 13 & Harmful Effects: Immune system 2 & 2.10 & $(1.52)$ & 23.33 & 5.00 & -0.04 & -1.10 & $0.69^{* *}$ \\
\hline 14 & Physiological Effects: SE4 (Embarrassment) & 0.79 & $(1.10)$ & 56.67 & 0.83 & 1.31 & 1.02 & $0.48^{* *}$ \\
\hline 15 & Physiological Effects: Tolerance 2 & 2.53 & (1.48) & 12.50 & 8.33 & -0.19 & -0.90 & $0.59^{* *}$ \\
\hline 16 & Physiological Effects: Monitor 2 & 2.37 & $(1.47)$ & 15.83 & 6.67 & -0.16 & -0.87 & $0.68^{* *}$ \\
\hline 17 & Physiological Effects: SE5 (Constipation) & 1.90 & (1.48) & 25.00 & 5.83 & 0.25 & -0.81 & $0.57^{* *}$ \\
\hline 18 & Communication: Distract MD 2 & 0.86 & $(1.23)$ & 56.67 & 2.50 & 1.51 & 1.81 & $0.54^{* *}$ \\
\hline 19 & Harmful Effects: Immune system 3 & 1.85 & (1.48) & 27.50 & 4.17 & 0.20 & -0.99 & $0.70^{* *}$ \\
\hline 20 & Physiological Effects: SE6 (general item) & 1.52 & (1.49) & 35.83 & 5.00 & 0.64 & -0.61 & $0.43^{* *}$ \\
\hline 21 & Physiological Effects: Tolerance 3 & 1.76 & $(1.50)$ & 25.83 & 5.00 & 0.47 & -0.84 & $0.72^{* *}$ \\
\hline 22 & Physiological Effects: Monitor 3 & 2.36 & (1.58) & 17.50 & 10.00 & -0.04 & -1.06 & $0.78^{* *}$ \\
\hline 23 & Harmful Effects: Addiction 3 & 2.54 & $(1.51)$ & 12.50 & 9.17 & -0.19 & -0.94 & $0.74^{* *}$ \\
\hline 24 & Fatalism 3 & 1.05 & $(1.15)$ & 35.83 & 3.33 & 1.62 & 3.15 & 0.14 \\
\hline 25 & Communication: Be good 2 & 0.91 & $(1.27)$ & 57.50 & 0.83 & 1.20 & 0.31 & $0.53^{* *}$ \\
\hline 26 & Communication: Distract MD 3 & 0.68 & (1.04) & 60.83 & 0.83 & 1.74 & 3.00 & $0.51^{* *}$ \\
\hline 27 & Communication: Be good 3 & 1.21 & (1.45) & 46.67 & 2.50 & 1.00 & -0.16 & $0.32^{* *}$ \\
\hline 28 & Disease Progression 1 & 3.30 & $(1.26)$ & 3.33 & 18.33 & -0.64 & 0.15 & $0.25^{* *}$ \\
\hline 29 & Disease Progression 2 & 3.40 & (1.18) & 1.67 & 20.00 & -0.55 & 0.11 & $0.36^{* *}$ \\
\hline 30 & Disease Progression 3 & 3.24 & $(1.15)$ & 0.83 & 15.00 & -0.32 & -0.27 & $0.37^{* *}$ \\
\hline
\end{tabular}

attem-total correlation ${ }^{* * P}<0.01$

\section{Test-retest reliability}

Table 4 shows the results of the test-retest. A significant correlation was identified after calculating the Spearman rank correlation coefficient $(\rho)$ for total JBQ-II scores and each subscale. The coefficient for Factor $\mathrm{V}$ was $\rho=0.49$, but that of all other factors were $\rho>0.7$, indicating that the results can be replicated.

\section{Validation verification}

\section{Construct validity}

The construct validity of the JBQ-II was examined by exploratory factor analysis using the principal method and promax rotation (Table 3). Table 5 shows the differences between the BQ-II and the JBQ-II. The three additional disease progression items were an independent factor, whereas the structure of the other four factors did not differ markedly from the original BQ-II. Seven items from one factor in the BQ-II were moved to a different factor in the JBQ-II (Table 5). There were no major changes to the content.

The cumulative contribution rate up to Factor $\mathrm{V}$ was 59.33. As the gradient on the scree plot became smaller after Factor V, it was hypothesized that the JBQ-II had a five-factor structure. Factor analysis (specifying five factors) confirmed this structure (Table 3). Each item had sufficient factor loading ( 0.40 or more), except for one item (item 14). The ratio explaining the total variance of the $30 \mathrm{JBQ}-\mathrm{II}$ 
Table 3 Factor analysis of the Japanese version of the Barriers Questionnaire-II completed by patients (main factor method: promax rotated factor pattern) and confidence coefficients

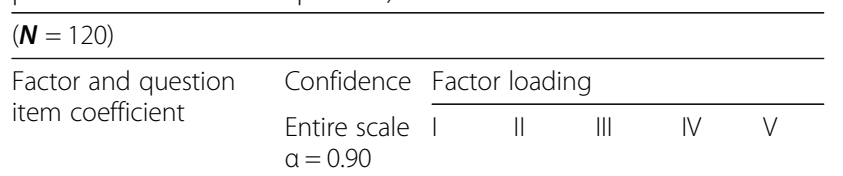

\section{Factor I: Physiological Effects}

7. Physiological Effects: Monitor 1

15. Physiological Effects: Tolerance 2

2. Harmful Effects: Addiction 1

16. Physiological Effects: Monitor 2

9. Harmful Effects: Addiction 2

6. Physiological Effects: Tolerance 1

21. Physiological Effects: Tolerance 3

23. Harmful Effects: Addiction 3

3. Physiological

Effects: SE1

(Drowsiness)

10. Physiological Effects: SE3 (Nausea)

22. Physiological

Effects: Monitor 3

\section{Factor II: \\ Communication}

26. Communication: Distract MD 3

12. Communication: Distract MD

11. Communication: Be good 1

20. Physiological Effects: SE6 (general item)

27. Communication: Be good 3

25. Communication: Be good 2

18. Communication: Distract MD 2

Factor III: Harmful Effects

4. Harmful Effects: Immune system 1

13. Harmful Effects: Immune system 2

19. Harmful Effects:

$a=0.89$

$$
\begin{array}{llllll}
. \mathbf{8 3 4} & -.017 & -.074 & -.114 & .039 \\
\mathbf{. 7 8 4} & -.060 & -.234 & .160 & .248 \\
\mathbf{. 6 4 9} & -.046 & .091 & -.064 & -.278 \\
\mathbf{. 6 2 4} & .054 & .062 & .040 & .080 \\
\mathbf{. 6 0 4} & -.015 & .080 & .007 & -.064 \\
\mathbf{. 5 9 2} & -.146 & .203 & .025 & .187 \\
\mathbf{. 5 2 3} & .261 & -.011 & .116 & .117 \\
& & & & \\
\mathbf{. 5 1 1} & .127 & .104 & .259 & -.016 \\
\mathbf{. 4 8 2} & -.089 & .069 & -.166 & -.145 \\
& & & & \\
\mathbf{. 4 3 0} & .014 & .121 & -.165 & -.015 \\
\mathbf{. 4 0 1} & .247 & .163 & .177 & .047
\end{array}
$$

$a=0.78$

$198 \quad 943 \quad 001-0.020 \quad .018$

$$
\begin{array}{lllll}
.257 & .680 & -.193 & -.125 & -.071
\end{array}
$$

\begin{tabular}{|c|c|c|c|c|c|c|}
\hline \multicolumn{7}{|l|}{$(\boldsymbol{N}=120)$} \\
\hline \multirow{2}{*}{$\begin{array}{l}\text { Factor and question } \\
\text { item coefficient }\end{array}$} & \multirow{2}{*}{$\begin{array}{l}\text { Confidence } \\
\text { Entire scale } \\
a=0.90\end{array}$} & \multicolumn{5}{|c|}{ Factor loading } \\
\hline & & I & $\|$ & III & IV & V \\
\hline \multicolumn{7}{|l|}{ Immune system 3} \\
\hline $\begin{array}{l}\text { 17. Physiological } \\
\text { Effects: SE5 } \\
\text { (Constipation) }\end{array}$ & & .001 & .146 & .492 & .010 & .079 \\
\hline $\begin{array}{l}\text { 5. Physiological } \\
\text { Effects: SE2 } \\
\text { (Confusion) }\end{array}$ & & .221 & .180 & .407 & .050 & .015 \\
\hline $\begin{array}{l}\text { 14. Physiological } \\
\text { Effects: SE4 } \\
\text { (Embarrassment) }\end{array}$ & & .116 & .151 & .296 & .042 & -.080 \\
\hline $\begin{array}{l}\text { Factor IV: Disease } \\
\text { Progression }\end{array}$ & $a=0.92$ & & & & & \\
\hline $\begin{array}{l}\text { 29. Disease } \\
\text { Progression } 2\end{array}$ & & -.101 & .043 & -.032 & .963 & -.089 \\
\hline $\begin{array}{l}\text { 30. Disease } \\
\text { Progression } 3\end{array}$ & & -.012 & -.041 & -.032 & .939 & -.094 \\
\hline $\begin{array}{l}\text { 28. Disease } \\
\text { Progression } 1\end{array}$ & & .021 & -.262 & .013 & .863 & -.094 \\
\hline Factor V: Fatalism & $a=0.73$ & & & & & \\
\hline 1. Fatalism 1 & & .121 & -.014 & -.017 & -.121 & .716 \\
\hline 8. Fatalism 2 & & -.049 & -.060 & -.075 & -.016 & .704 \\
\hline 24. Fatalism 3 & & .041 & -.125 & .049 & -.201 & .657 \\
\hline Factor correlation & & । & $\|$ & III & IV & V \\
\hline I & & - & .365 & .600 & .394 & .083 \\
\hline$\|$ & & & - & .539 & .238 & .365 \\
\hline III & & & & - & .197 & .203 \\
\hline IV & & & & & - & .101 \\
\hline V & & & & & & - \\
\hline
\end{tabular}$$
\begin{array}{lllll}
.012 & .654 & -.021 & -. .155 & -.084
\end{array}
$$$$
\begin{array}{lllll}
.159 & .561 & -.029 & -.087 & -.288
\end{array}
$$

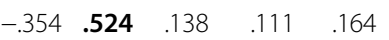$$
\begin{array}{lllll}
-.118 & .508 & .150 & .066 & .311
\end{array}
$$$$
\begin{array}{lllll}
.238 & .461 & .023 & -.038 & -.118
\end{array}
$$

$a=0.86$

$$
\begin{array}{cccccc}
.018 & -.106 & \mathbf{1 . 0 3 4} & -.103 & -.065 \\
.109 & -.069 & .822 & -.004 & -.028 \\
& & & & \\
.210 & -.018 & .614 & .038 & .049
\end{array}
$$

Table 3 Factor analysis of the Japanese version of the Barriers Questionnaire-II completed by patients (main factor method: promax rotated factor pattern) and confidence coefficients (Continued)

Table 4 Test-retest results for the Japanese version of the Barriers Questionnaire-II

\begin{tabular}{lllllll}
\hline & \multicolumn{2}{l}{ Test $(n=21)$} & & \multicolumn{2}{l}{ Retest $(n=21)$} & \\
\cline { 2 - 3 } & Mean & SD & & Mean & SD & $P$ \\
\hline Total JBQ-II scores & 50.05 & 21.86 & & 49.71 & 21.18 & $.88^{* *}$ \\
Factor I & 24.90 & 11.22 & 23.49 & 16.37 & $.72^{* *}$ \\
Factor II & 5.90 & 5.56 & 5.86 & 5.69 & $.88^{* *}$ \\
Factor III & 9.71 & 7.87 & 8.95 & 7.28 & $.85^{* *}$ \\
Factor IV & 9.48 & 3.79 & & 8.61 & 4.14 & $.75^{* *}$ \\
$\quad$ Factor $V$ & 2.60 & 2.36 & & 1.90 & 1.51 & $.49^{*}$ \\
\hline **P<0.01 ${ }^{*} P<0.05$ & & & & &
\end{tabular}


Table 5 Differences between Barriers Questionnaire-II and Japanese version of the Barriers Questionnaire-II factors

\begin{tabular}{lll}
\hline Item & BQ-II & JBQ-II \\
\hline 5. Physiological Effects: SE2 (Confusion) & Factor & Factor \\
14. Physiological Effects: SE4 (Embarrassment) & I & III \\
17. Physiological Effects: SE5 (Constipation) & । & III \\
20. Physiological Effects: SE6 (general item) & । & II \\
2. Harmful Effects: Addiction 1 & III & । \\
9. Harmful Effects: Addiction 2 & III & । \\
23. Harmful Effects: Addiction 3 & III & ।
\end{tabular}

items over five factors (before rotation) was 52.29\%. Path analysis showed that valid paths that fit the construct could be drawn for all characteristics, excluding education and age (Fig. 1).

\section{Discriminant validity}

Table 6 shows the results of the known group analysis. The null hypothesis was refuted for all factors and total scores. Compared with health professional participants, patients with cancer had significantly higher barriers to pain management, thus indicating discriminant validity.

\section{Criterion-related validity}

The analysis of the JBQ-II and K6 showed a weak relationship between Factor II (communication) and the $\mathrm{K} 6$ $(r=0.20, P<0.05)$. Creating two segments for PMI, from -3 to -1 ("Group not using analgesics sufficiently") and from 0 to 3 ("Group using analgesics sufficiently") and conducting a sub-analysis showed that the total JBQ-II score had weak positive correlations with the $\mathrm{K} 6$, indicating a poor emotional state $(r=0.36, P<0.01)$. This demonstrated that patient-related barriers have a weak relationship with emotional state, and indicated the JBQ-II had criterion-related validity.

Table 6 Discriminant validity of the Japanese Barriers Questionnaire-II

\begin{tabular}{|c|c|c|c|c|c|}
\hline \multirow[t]{2}{*}{ Factor } & \multicolumn{2}{|c|}{ Health professionals $(n=21)$} & \multicolumn{2}{|c|}{ Patients $(n=120)$} & \multirow[b]{2}{*}{$P$} \\
\hline & Mean & $S D$ & Mean & $S D$ & \\
\hline । & 8.45 & 7.97 & 27.52 & 10.89 & $<.0001$ \\
\hline$\|$ & 5.45 & 3.97 & 7.23 & 6.19 & $<.0001$ \\
\hline III & 1.65 & 2.01 & 11.09 & 6.59 & $<.001$ \\
\hline IV & 4.90 & 3.37 & 9.94 & 3.35 & $<.0001$ \\
\hline V & 1.65 & 1.57 & 3.35 & 2.73 & $<.001$ \\
\hline Total score & 22.10 & 14.79 & 59.18 & 21.22 & $<.0001$ \\
\hline
\end{tabular}

\section{Feasibility}

In total, 87 patients (72.5\%) reported that the question content was clear and easy to understand, 93 (77.5\%) reported that answering the questions was clear, and 85 (70.8\%) reported that the questions were clear to understand and answer. The length of time needed to answer the JBQ-II ranged from 2 to 20 min (mean $8.34 \pm 4.18$ ), which confirmed the feasibility of the instrument.

\section{Discussion}

The overall results showed that the JBQ-II was a reliable and valid instrument for measuring barriers to pain management in Japanese adult patients with cancer. Regarding reproducibility, Factor IV (disease progression) showed a rather low Spearman's correlation coefficient of 0.49; however, this result might have been affected by patients' emotional state, symptoms, or condition. The internal consistency of Factor II: Communication and Factor V: Fatalism was slightly lower. Some of the items may have different characteristics than others, but from a content perspective, it makes sense that they belong to the same category. From a holistic perspective of scale, it is a necessary item for observing barriers.

In the factor analysis, some BQ-II items were moved to a different factor in the JBQ-II. Other countries' versions also differ somewhat in terms of the number of questions and how the sub-scales are divided, but the content of the subordinate construct is virtually identical, and the barriers are evaluated stably from the same viewpoint worldwide [913]. Patients' perception of barriers may therefore reflect cultural backgrounds. However, the content of the subordinate construct was virtually identical across versions, and the barriers were evaluated from similar perspectives worldwide. The constructive concept of the JBQ-II was also virtually the same as that of versions used in other countries. Therefore, it may be considered appropriate as a newly developed scale that reflects cultural background and can measure barriers to pain management in Japan.

The present findings indicated that harmful occurrences or physiological effects might differ depending on the individual's habits or experiences. It is plausible that the JBQII reflects cultural differences regarding awareness of harmful occurrences or physiological effects. In the original questionnaire, subcategories for harmful occurrences included worries about weakening the immune system and concerns about dependence; in Japan, worries viewed as harmful occurrences included weakening the immune system, constipation, and loss of social function or impact on relationships with other people (e.g., confusion or worry about doing something embarrassing).

The path analysis substantiated causal relationships between the JBQ-II $\rightarrow$ PMI $\rightarrow$ QoL (Fig. 1), although the path coefficient was low. This suggested that when barriers are high, PMI is low (i.e., inadequate use of analgesics; patient 
experiences pain) and QoL is affected. As found in previous research [5], no significant path could be drawn where education and age were concerned. However, the characteristic that many of the Japanese respondents were relatively well educated might have influenced the results.

To test the criterion-related validity, we needed to select an external index because there are no indices for the JBQ-II and outcomes. The results showed a correlation between Factor II (communication) and poor emotional state, which is consistent with previous research [5]. Stratification showed a weak correlation between barriers and K6-related external indices (poor emotional state). As there is no evaluation tool in Japan for criterion-related validity, other assessment criteria need to be developed.

This study demonstrated that the JBQ-II can be applied in daily practice. However, as the present study was conducted in a single institution, similar surveys need to be conducted and verified across other settings to assure the generalizability of the findings. The relationship between patient-related barriers and other factors as well as culturally specific barriers should also be further investigated.

\section{Limitations}

There are several limitations to our study. First, this study was conducted in a single institution in Tokyo Japan. Our results may not be applicable other settings. Similar surveys should be conducted in other institutions and regions. A future challenge is to increase the frequency of use and improve the survey's practical aspects on an ongoing basis. Second, we considered subjective health, emotional state (K6), and daily life (BPI) as potential QoL variables. Therefore, the results might differ if other definitions or a QoL scale were used. Despite these limitations, we conducted multifaceted evaluations of the JBQ-II. Our findings may be useful to assess pain in clinical settings, as well as for epidemiological studies of cancer pain management. It is necessary to provide care that recognizes the presence of barriers to pain management. In addition, from a global perspective, there are many barriers to pain management in Asian and developing countries, which may differ by culture and ethnicity. We believe validated instruments such as the BQ-II need to be available across various languages to integrate global trends.

\section{Conclusion}

The JBQ-II has construct, criterion-referenced, and discriminant validity, and is a reliable and valid index for assessing barriers to pain management among Japanese adult patients with cancer. Therefore, the JBQ-II may be used routinely to improve pain management in Japan.

\section{Abbreviations}

BQ-\|: Barriers Questionnaire II: JBQ-\|: Japanese version of the Barriers

Questionnaire II; ICC: Intra-class correlation coefficient; BPI-J: Japanese version of the Brief Pain Inventory; K6: Six-item Kessler Psychological Distress Scale; PMl: Pain Management Index; QoL: Quality of life

\section{Acknowledgments}

We thank patients, health professionals and everyone who cooperated and participated in this study. We also thank Audrey Holmes, MA, from Edanz Group (www.edanzediting.com/ac) for editing a draft of this manuscript.

\section{Authors' contributions}

NS and HK designed the study; NS, MT, HY, and TY were responsible for participant recruitment and data generation; NS, HK, and AZD analyzed and interpreted the data. All authors contributed to the manuscript preparation and approved the final version of the manuscript.

\section{Funding}

This work was supported in part by the National Institute of Nursing Research of the National Institutes of Health [award number K24NR015340].

Availability of data and materials Not applicable.

\section{Ethics approval and consent to participate}

The study protocol was approved by the Institutional Review Boards of Keio University (No. 2012-10) and St. Luke's International Hospital (No. 12-R066). Informed consent was obtained in written by all participants before participating in the study.

\section{Consent for publication}

Not applicable.

\section{Competing interests}

The authors have no conflicts of interest to declare.

\section{Author details}

${ }^{1}$ Analysis Section, Center for Cancer Registries, Center for Cancer Control and Information Services, National Cancer Center Japan, 5-1-1 Tsukiji, Chuo-ku, Tokyo 104-0045, Japan. St. Luke's International Hospital, 9-1 Akashi-cho,

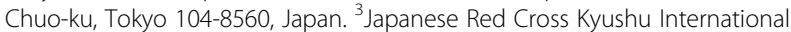
College of Nursing, 1-1 Asty Munakata-City, Fukuoka 811-4157, Japan. ${ }^{4}$ Nursing Department, St. Luke's International Hospital, 9-1 Akashi-cho, Chuo-ku, Tokyo 104-8560, Japan. ${ }^{5}$ Breast Surgery, St. Luke's International Hospital, 9-1 Akashi-cho, Chuo-ku, Tokyo 104-8560, Japan. ${ }^{6}$ Medical Oncology, St. Luke's International hospital, 9-1 Akashi-cho, Chuo-ku, Tokyo 104-8560, Japan. ${ }^{7}$ Department of Biobehavioral Health Science, College of Nursing, University of Illinois at Chicago, Chicago, USA. ${ }^{8}$ Palliative Care, University of Illinois Cancer Center, 845 S. Damen Ave., Chicago, Illinois 60612, USA.

Received: 6 November 2019 Accepted: 26 June 2020

Published online: 09 July 2020

\section{References}

1. Sheinfeld Gorin S, Krebs P, Badr H, Janke EA, Jim HS, Spring B, Mohr DC, Berendsen MA, Jacobsen PB. Meta-analysis of psychosocial interventions to reduce pain in patients with cancer. J Clin Oncol. 2012;30(5):539-47.

2. Akiyama M, Takebayashi T, Morita T, Miyashita M, Hirai K, Matoba M, Akizuki $\mathrm{N}$, Shirahige Y, Yamagishi A, Eguchi K. Knowledge, beliefs, and concerns about opioids, palliative care, and homecare of advanced cancer patients: a nationwide survey in Japan. Support Care Cancer. 2012;20(5):923-31.

3. Ward SE, Goldberg N, Miller-McCauley V, Mueller C, Nolan A, Pawlik-Plank D, Robbins A, Stormoen D, Weissman DE. Patient-related barriers to management of cancer pain. Pain. 1993;52(3):319-24.

4. Gunnarsdottir S, Donovan HS, Serlin RC, Voge C, Ward S. Patient-related barriers to pain management: the barriers questionnaire II (BQ-II). Pain. 2002; 99(3):385-96.

5. Ward SE, Carlson-Dakes K, Hughes SH, Kwekkeboom KL, Donovan HS. The impact on quality of life of patient-related barriers to pain management. Res Nurs Health. 1998;21(5):405-13.

6. Saifan A, Bashayreh I, Batiha AM, AbuRuz M. Patient- and family caregiverrelated barriers to effective cancer pain control. Pain Manage Nurs. 2015; 16(3):400-10. 
7. Valeberg BT, Miaskowski C, Paul SM, Rustoen T. Comparison of oncology Patients' and their family Caregivers' attitudes and concerns toward pain and pain management. Cancer Nurs. 2016;39(4):328-34.

8. Jahn P, Kuss O, Schmidt H, Bauer A, Kitzmantel M, Jordan K, Krasemann S, Landenberger M. Improvement of pain-related self-management for cancer patients through a modular transitional nursing intervention: a clusterrandomized multicenter trial. Pain. 2014;155(4):746-54.

9. Kwon JH, Oh SY, Chisholm G, Lee JA, Lee JJ, Park KW, Nam SH, Song HH, Lee $K$, Zang DY, et al. Predictors of high score patient-reported barriers to controlling cancer pain: a preliminary report. Support Care Cancer. 2013; 21(4):1175-83.

10. Bagcivan G, Tosun N, Komurcu S, Akbayrak N, Ozet A. Analysis of patientrelated barriers in cancer pain management in Turkish patients. J Pain Symptom Manag. 2009;38(5):727-37.

11. Gunnarsdottir S, Serlin RC, Ward S. Patient-related barriers to pain management: the Icelandic barriers questionnaire II. J Pain Symptom Manag. 2005;29(3):273-85.

12. Jacobsen R, Moldrup C, Christrup L, Sjogren P, Hansen OB. The Danish barriers questionnaire-II: preliminary validation in cancer pain patients. Pain Pract. 2009;9(4):266-74.

13. Valeberg BT, Hanestad BR, Klepstad P, Miaskowski C, Moum T, Rustoen T. Cancer patients' barriers to pain management and psychometric properties of the Norwegian version of the barriers questionnaire II. Scand J Caring Sci. 2009;23(3):518-28.

14. Cleeland CS, Ryan KM. Pain assessment: global use of the brief pain inventory. Ann Acad Med Singap. 1994;23(2):129-38.

15. Cleeland CS, Nakamura Y, Mendoza TR, Edwards KR, Douglas J, Serlin RC. Dimensions of the impact of cancer pain in a four country sample: new information from multidimensional scaling. Pain. 1996;67(2-3):267-73.

16. Philip J, Smith WB, Craft P, Lickiss N. Concurrent validity of the modified Edmonton symptom assessment system with the Rotterdam symptom checklist and the brief pain inventory. Support Care Cancer. 1998;6(6):539-41.

17. Radbruch L, Loick G, Kiencke P, Lindena G, Sabatowski R, Grond S, Lehmann KA, Cleeland CS. Validation of the German version of the brief pain inventory. J Pain Symptom Manag. 1999;18(3):180-7.

18. Keller S, Bann CM, Dodd SL, Schein J, Mendoza TR, Cleeland CS. Validity of the brief pain inventory for use in documenting the outcomes of patients with noncancer pain. Clin J Pain. 2004;20(5):309-18.

19. Uki J, Mendoza T, Cleeland CS, Nakamura Y, Takeda F. A brief cancer pain assessment tool in Japanese: the utility of the Japanese brief pain inventory--BPI-J. J Pain Symptom Manag. 1998;16(6):364-73.

20. Deandrea S, Montanari M, Moja L, Apolone G. Prevalence of undertreatment in cancer pain. A review of published literature. Ann Oncol. 2008;19(12): 1985-91.

21. Greco MT, Roberto A, Corli O, Deandrea S, Bandieri E, Cavuto S, Apolone G. Quality of cancer pain management: an update of a systematic review of undertreatment of patients with cancer. J Clin Oncol. 2014:32(36):4149-54.

22. Cleeland CS, Gonin R, Hatfield AK, Edmonson JH, Blum RH, Stewart JA, Pandya KJ. Pain and its treatment in outpatients with metastatic cancer. N Engl J Med. 1994;330(9):592-6.

23. Kessler RC, Barker PR, Colpe LJ, Epstein JF, Gfroerer JC, Hiripi E, Howes MJ, Normand SL, Manderscheid RW, Walters EE, et al. Screening for serious mental illness in the general population. Arch Gen Psychiatry. 2003;60(2): 184-9.

24. Furukawa TA, Kessler RC, Slade T, Andrews G. The performance of the K6 and $\mathrm{K} 10$ screening scales for psychological distress in the Australian National Survey of mental health and well-being. Psychol Med. 2003;33(2): $357-62$

25. Nakano K, Yabe J, Yasumura S. Health practice and total mortality among middle-aged and elderly residents in Sukagawa, Japan. Nihon Koshu Eisei Zasshi. 2006;53(5):329-37.

\section{Publisher's Note}

Springer Nature remains neutral with regard to jurisdictional claims in published maps and institutional affiliations.

\section{Ready to submit your research? Choose BMC and benefit from:}

- fast, convenient online submission

- thorough peer review by experienced researchers in your field

- rapid publication on acceptance

- support for research data, including large and complex data types

- gold Open Access which fosters wider collaboration and increased citations

- maximum visibility for your research: over $100 \mathrm{M}$ website views per year

At BMC, research is always in progress.

Learn more biomedcentral.com/submissions 